\title{
MHC-Linked Olfactory Receptor Loci Exhibit Polymorphism and Contribute to Extended HLA/OR-Haplotypes
}

\author{
Anke Ehlers, ${ }^{1}$ Stephan Beck, ${ }^{2}$ Simon A. Forbes, ${ }^{3}$ John Trowsdale, ${ }^{3}$ Armin Volz, ${ }^{1}$ \\ Ruth Younger, ${ }^{2}$ and Andreas Ziegler ${ }^{1,4}$ \\ ${ }^{1}$ Institut für Immungenetik, Universitätsklinikum Charité, Humboldt-Universität zu Berlin, 14050 Berlin, Germany; \\ ${ }^{2}$ The Sanger Centre, Wellcome Trust Genome Campus, Hinxton, Cambridge CB10 1SA, UK; ${ }^{3}$ Department of Pathology, \\ Division of Immunology, University of Cambridge, Cambridge CB2 1QP, UK
}

\begin{abstract}
Clusters of olfactory receptor (OR) genes are found on most human chromosomes. They are one of the largest mammalian multigene families. Here, we report a systematic study of polymorphism of OR genes belonging to the largest fully sequenced OR cluster. The cluster contains 36 OR genes, of which two belong to the vomeronasal 1 (VI-OR) family. The cluster is divided into a major and a minor region at the telomeric end of the HLA complex on chromosome 6. These OR genes could be involved in MHC-related mate preferences. The polymorphism screen was carried out with 13 genes from the HLA-linked OR cluster and three genes from chromosomes 7, 17, and 19 as controls. Ten human cell lines, representing 18 different chromosome 6s, were analyzed. They were from various ethnic origins and exhibited different HLA haplotypes. All OR genes tested, including those not linked to the HLA complex, were polymorphic. These polymorphisms were dispersed along the coding region and resulted in up to seven alleles for a given OR gene. Three polymorphisms resulted either in stop codons (genes hs6Ml-4P, hs6Ml-17) or in a 16-bp deletion (gene hs6Ml-19P), possibly leading to lack of ligand recognition by the respective receptors in the cell line donors. In total, 13 HLA-linked OR haplotypes could be defined. Therefore, allelic variation appears to be a general feature of human OR genes.
\end{abstract}

[The sequence data reported in this paper have been submitted to EMBL under accession nos. AC006137, AC004178, A]132194, AL022727, AL031983, AL035402, AL035542, Z98744, CAB55431, AL050339, AL035402, AL096770, AL133267, AL121944, Z98745, AL021808, and AL021807.]

Studies on inbred mice and rats have shown that products of MHC genes influence individual-specific odors (Yamazaki et al. 1979, 1999; Singh et al. 1987; Brown et al. 1989; Penn and Potts 1998a; for review, see Penn and Potts 1998b), which play an important role in mate choice (Yamazaki et al. 1976; Potts et al. 1991; Penn and Potts 1998c): MHC-dissimilar mating partners are preferred. It has even been demonstrated that the reproductive performance of mice can be influenced via urine odors by a discrete point mutation in the H-2K gene (Yamazaki et al. 1986). A preference for MHC-dissimilar odor types has also been reported for humans: Odors were rated the more attractive the fewer HLA-class I antigens were shared by the provider of the odor and its recipient (Wedekind et al. 1995; Wedekind and Füri 1997). Although currently unproven, an interaction between the products of MHC genes or molecules associated with them and linked OR loci, as suggested by Yamazaki and colleagues

${ }^{4}$ Corresponding author.

E-MAIL andreas.ziegler@charite.de; FAX 49-30-450-53953.

Article and publication are at www.genome.org/cgi/doi/10.1101/ gr.120400.
(1976), could have evolved either to avoid the disadvantages connected with inbreeding or to favor the selection of an MHC-divergent partner leading to MHC-heterozygous offspring with improved protection against attack by parasites (Potts and Wakeland 1993; Beauchamp and Yamazaki 1997; Penn and Potts 1998b). Linked genes controlling mating preferences are not uncommon in other phyla: For example, in the mating and sexual development of the mushroom Coprinus cinereus, several closely linked polymorphic pheromone and pheromone receptor genes determine B mating-type specificities (O'Shea et al. 1998).

Vertebrates have evolved two chemosensory systems that are able to discriminiate a large array of scents: the main olfactory epithelium (MOE) and the vomeronasal organ (VNO). The MOE apears to discriminate odors from the environment (conscious odor perception; Zhao et al. 1998), whereas receptors expressed in the VNO appear to recognize substances such as pheromones that result in behavioral responses that do not involve higher cognitive centers of the brain (subconscious odor perception; Wysocki 1989; Leinders-Zufall et al. 2000). The OR of the VNO belong 
to two distinct families (V1-OR and V2-OR) of $~ 50-100$ genes each (Dulac and Axel 1995; Herrada and Dulac 1997; Matsunami and Buck 1997), while the family of the unrelated MOE-expressed OR (M-OR) genes contains up to 1000 members in mammals, including man (Buck and Axel 1991). The three types of polypeptides are G-protein-coupled receptors (GPCR) with putative seven transmembrane domains (TM1-TM7); they comprise also extracellular (EC1-EC4) and cytoplasmatic regions (CP1-CP4).

In humans, M-OR genes are located on nearly all chromosomes (Rouquier et al. 1998b), and a few M-OR loci in close linkage to the HLA-F locus were described several years ago (Fan et al. 1995; Gruen et al. 1996). We have recently demonstrated that at least 36 OR genes, two of them of the V1-OR type and the rest $\mathrm{M}$-OR loci, are located in the immediate vicinity of the HLA-F locus in one major and one minor cluster (Younger et al. 2000; Ziegler et al. 2000a). Alleles of these genes would be subject to the strong linkage disequilibrium that is a characteristic feature of this chromosomal region (Malfroy et al. 1997; Tay et al. 1997; Naruse et al. 1998). So far, allelic variations of human OR genes have not been described (Mombaerts $1999 a, b)$, although such variations might be expected to contribute to individual odor perception. They could be particularly pronounced for OR genes in close linkage to the highly polymorphic HLA class I loci.

To provide a foundation for further studies, this work aims to determine whether OR genes, and in particular those in HLA-linkage, exhibit polymorphisms. To this end, we have concentrated on the potentially expressible M-OR genes with open reading frames (ORF) and investigated whether allelic variation is a regular feature of these loci. Thirteen HLA-linked and, for comparison, three OR genes from chromosomes 7, 17 , and 19 were analyzed in detail using 10 cell lines from different ethnic origins and with different HLA haplotypes. The results indicate that all M-OR loci analyzed are polymorphic.

\section{RESULTS}

\section{Genomic Organization of HLA-Linked OR Genes}

The MHC-linked OR clusters contain at least 36 OR loci (a detailed account of the genomic organization will be published elsewhere [Younger et al. 2000]), 34 of which are members of the M-OR family, and two of which are of the V1-OR type (Fig. 1). From sequencing of PACs and BACs covering the region telomeric of HLA-F, 15 of the identified M-OR genes (hs6M1-1, -3, $-6,-10,-12,-15,-16,-17,-18,-20,-21,-27,-28,-32,-35)$ showed complete open reading frames (ORFs) of the expected length and, therefore, were predicted to be functional. The remaining 19 loci ( $h s 6 M 1-2 P,-4 P,-5 P$, $-7 P,-8 P,-9 P,-13 P,-14 P,-19 P,-22 P,-23 P,-24 P,-25 P$,

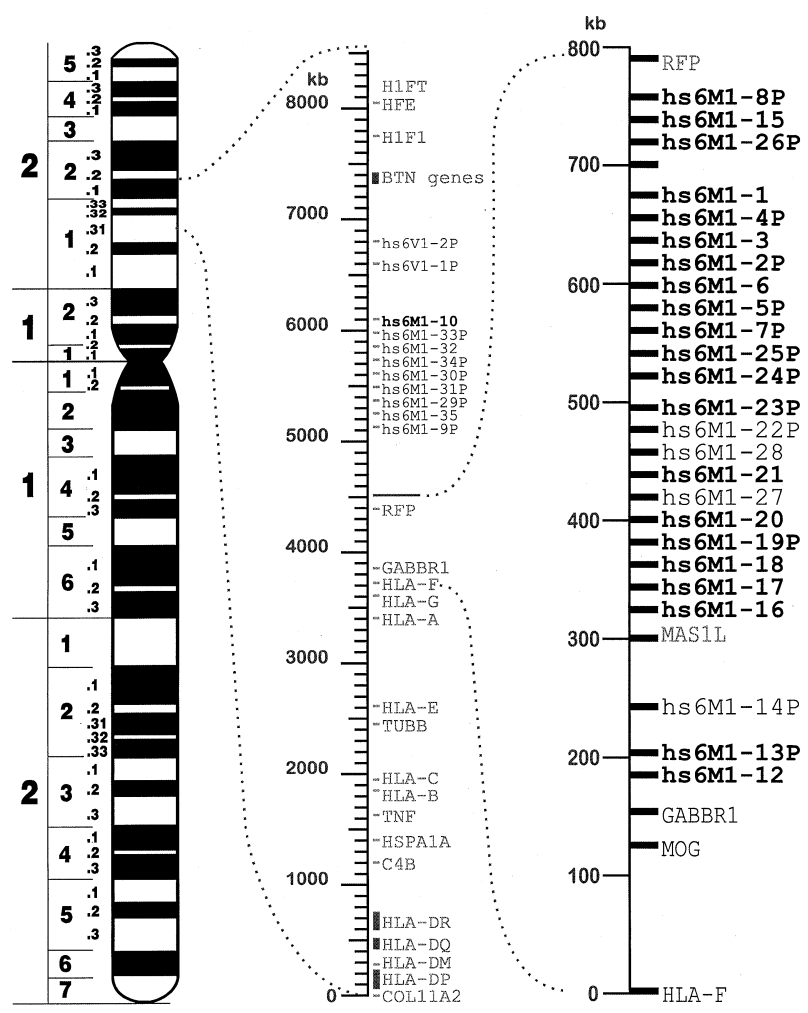

Figure 1 Chromosome 6 ideogram. All identified OR genes in the vicinity of the HLA complex ( $h$ s6M1-1 to $-35 P$, and the V1-OR type loci $h s 6 V 1-1 P,-2 P)$ and their approximate location on the physical map are indicated. The genes highlighted in bold type are those that have been analyzed here in more detail.

$-26 P,-29 P,-30 P,-31 P,-33 P,-34 P)$ appeared to be pseudogenes. With the exception of the hs6M1-10, -32, and -35 genes, all other OR loci with intact ORF were located in the major HLA-linked OR cluster between $H L A-F$ and RFP. The following $22 \mathrm{M}$-OR genes were analyzed in detail by sequencing: 21 are located within the $560 \mathrm{~kb}$ directly telomeric of the GABBR1 locus (Peters et al. 1998; Younger et al. 2000; hs6M1-1; -2P, -3, $-4 P,-5 P,-6,-7 P,-8 P,-12,-13 P,-15,-16,-17,-18,-19 P$, $-20,-21,-23 P,-24 P,-25 P,-26 P)$, whereas $h s 6 \mathrm{M} 1-10$ is part of the minor HLA-linked OR cluster distal of the RFP gene (Fig. 1). To compare the degree of polymorphism between HLA-linked and non-HLA-linked OR genes, three additional OR genes ( $h s 7 M 1-1, h s 17 M 1-20$, and $h s 19 M 1-4)$ located on chromosomes 7,17 , and 19, respectively, were investigated. Sequences were determined for all OR genes in 10 cell lines (Table 1) chosen from different ethnic groups and selected to possess distinct HLA class I haplotypes to maximize the chance of detecting polymorphisms in HLA-linked OR loci. The high degree of homology exhibited by some of the OR genes-for example, hs6M1-3 and hs6M1-6 or hs6M1-12 and hs6M1-16 (Younger et al. 2000; Ziegler et al. 2000b) -was taken into account during the design of primers for amplifications by PCR. 
Table 1. Nucleotide and Amino Acid Substitutions and Mutations

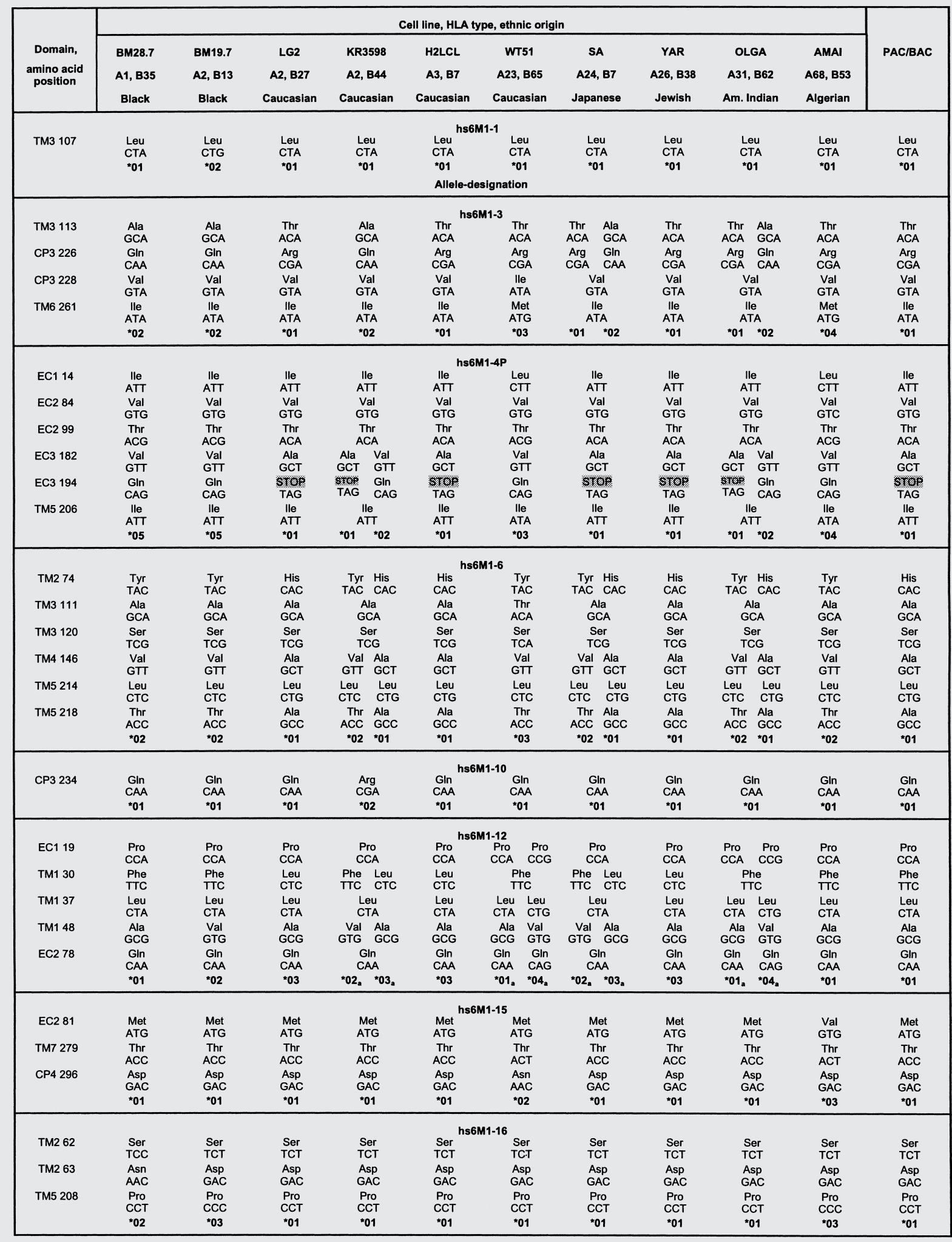

(Continues) 
Table 1. (Continued)

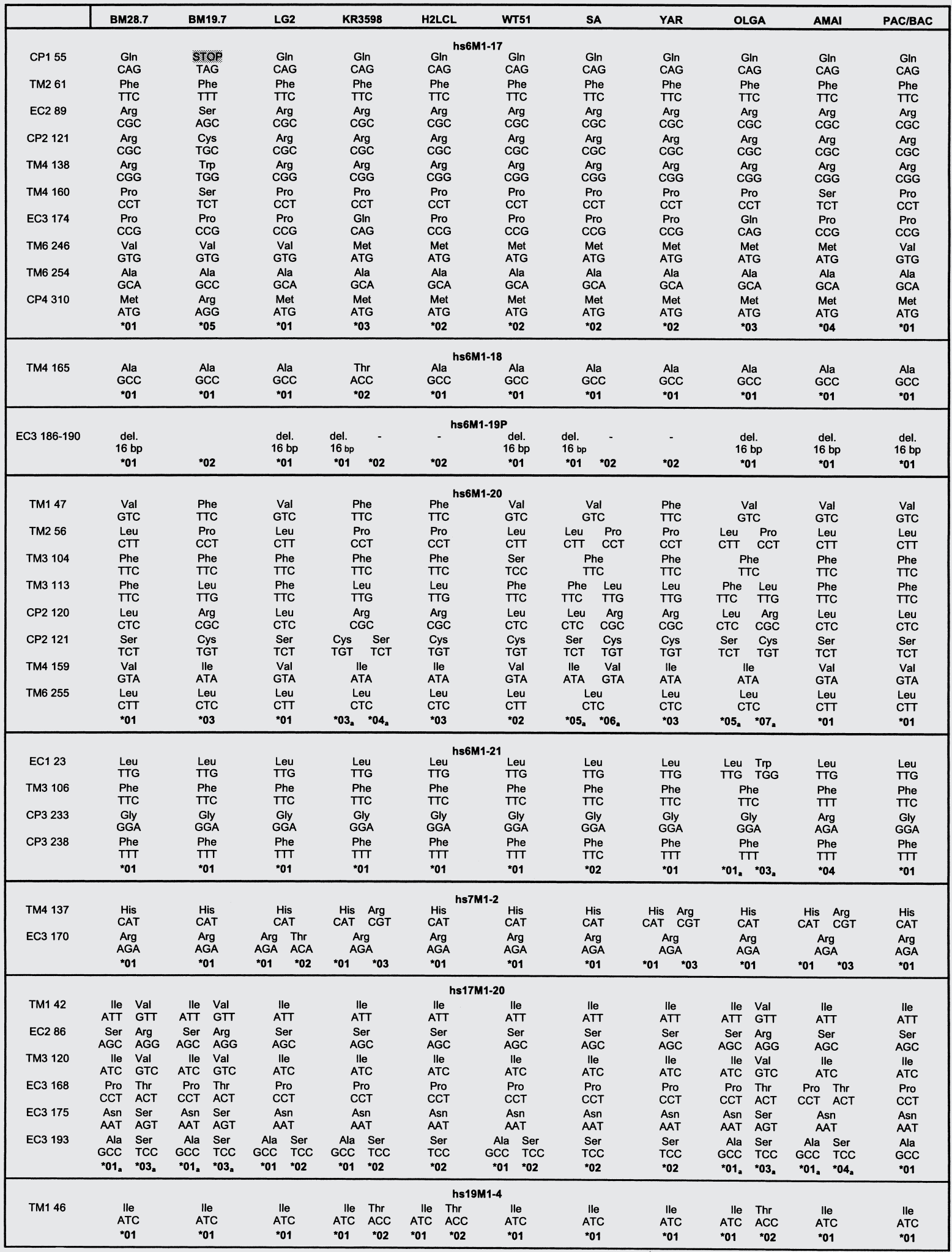

Nucleotide and amino acid substitutions and silent mutation within the different domains of the HLA-linked and non-HLA-linked OR genes leading to the indicated alleles. HLA class I haplotypes and ethnic origins of the analyzed cell lines are also indicated. ${ }^{\mathrm{a}}$ Most likely allele. 


\section{OR Pseudogenes}

Analysis of the PAC- or BAC-derived genomic sequences revealed that 17 of the HLA-linked OR loci, including several of them analyzed in detail on all 10 cell lines (hs6M1-2P, -7P, -8P, -13P, -23P, -24P, -25P, $-26 P$ ) could be characterized as pseudogenes because of frameshifts, in-frame stop codons, or missing start codon. For several of these pseudogenes, between one and three alleles were found (data not shown), differing only by 1 or $2 \mathrm{nt}$ in the respective cell lines (in the case of $h s 6 M 1-5 P,-24 P,-25 P$, and $-26 P$, only the regions containing the stop codon or frameshifts were sequenced).

\section{OR Genes With Open Reading Frames}

Fourteen of the tested genes (hs6M1-1, -3, -6, -10, -12, $-15,-16,-17,-18,-20,-21$; hs 7M1-2; hs17M1-20; hs19M1-4) showed an intact ORF-containing sequence for all domains as predicted by comparison with other known OR genes. Three of the HLA-linked genes appeared particularly interesting, as they exhibited intact ORFs in some of the cell lines but qualified as pseudogenes in others: hs6M1-4P, -17, and -19P (the gene status is defined here by the genomic sequence of the OR from the PAC or BAC used to obtain the original sequence information).

The 13 HLA-linked M-OR genes with ORF analyzed here (Table 1) exhibited 52 nucleotide substitutions altogether: 16 (31\%) were silent and $36(69 \%)$ resulted in a change in the amino acid sequence, while the hs6M119P gene exhibited a frameshift-generating deletion. Besides the hs6M1-1 gene, which showed only a single silent mutation, all other genes exhibited at least two alleles with different amino acid sequences in the 10 cell lines analyzed. Apart from the hs6M1-19P locus, the amino acid replacements were always based on single nucleotide substitutions in the respective codons. The polymorphisms within the OR genes occurred at different positions (Table 1; Fig. 2): for example, hs6M1-3 exhibited variations in TM3, CP3, and TM6, whereas in hs6M1-6, polymorphisms resulting in amino acid (AA) changes in TM2, 3, 4, and 5 were

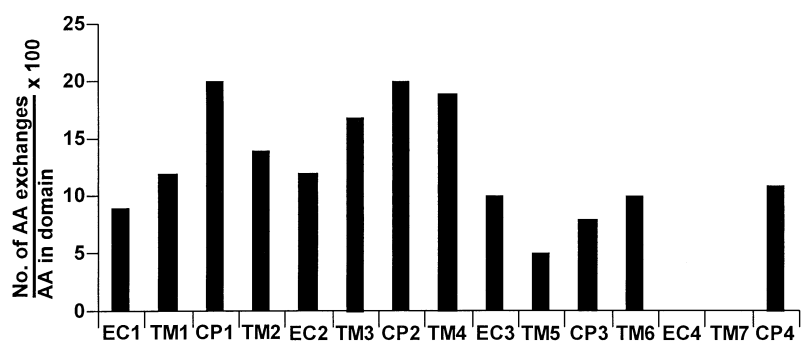

Figure 2 Frequency of polymorphisms leading to AA exchanges within all analyzed HLA-linked OR with ORF. The domains of the expressed proteins are plotted against the number of AA exchanges within these domains, expressed as a fraction of each domain's length. found, and $h s 6 \mathrm{M} 1-4 P$ was characterized by AA changes in the extracellular domains EC1 and EC3. However, exceptions to this finding were also observed: The variations of $h s 6 M 1-3$ (AA 113) and hs6M1-6 (AA 111) in TM3 were located at corresponding AA positions and used the same codons, a situation similar to that of hs6M1-20 (AA 104) and hs6M1-21 (AA 106), although the latter gene exhibited only a silent mutation at this position.

\section{Amino Acid Substitutions Within OR}

The frequency of these AA substitutions varied considerably. For example, the Ala146Val substitution in TM4 of hs6M1-6 was found on 11 of 19 chromosomes analyzed (including the PAC from which the sequence was derived), whereas other substitutions like the Ala111Thr change in TM3 of hs6M1-6 were found only in the two haplotypes from the WT51 cell line (Table 1). We detected conservative substitutions where both amino acids of the OR have similar properties, as in the case of the Ala182Val exchange in EC3 of hs6M1-4P as well as drastic substitutions like the Gln234Arg exchange in CP3 of hs6M1-10, leading to a change in the polarity of the residue. The three OR on chromosomes 7,17 , and 19 exhibited very similar properties. Each of them revealed polymorphisms that resulted in both conservative as well as nonconservative AA changes in the expected proteins. AA substitutions were not found in each of the protein domains, but this could be because of the small number of non-HLA-linked genes analyzed so far.

\section{OR Genes With Potentially Functional and Nonfunctional Alleles}

In the case of the OR genes $h s 6 \mathrm{M} 1-4 P$ and -17 , alleles (hs6M1-4P* 01 and $-17^{*} 05$, respectively) were found that are likely to give rise to nonfunctional protein products, while all other alleles at these loci are expected to be fully functional (Table 1). Yet another situation was observed for the hs6M1-19P gene: One of the two alleles found among the 10 cell lines and the original genomic sequence (hs6M1-19P* 01) had a 16bp deletion within TM4, resulting in a frameshift and a presumably nonfunctional OR protein, while the other allele exhibited an intact ORF. In contrast to the hs6M1-4P and -17 genes, no further polymorphisms were observed for this locus.

\section{Numbers of OR Alleles}

The number of alleles for each of the OR loci was also quite different (Table 2). While hs6M1-1, -10, -18, and $-19 P$ exhibited only two alleles (with the variation in hs6M1-1 resulting in no amino acid exchange), the other OR genes had three (hs6M1-6, -15, and -16), four (hs6M1-3, -12, and -21), five (hs6M1-4P and -17), or even seven (hs6M1-20) alleles, thus approaching the 
Table 2. OR Alleles and Haplotypes in the 10 Analyzed Cell Lines

\begin{tabular}{|c|c|c|c|c|c|c|c|c|c|c|c|c|c|c|c|c|}
\hline \multirow{2}{*}{$\begin{array}{l}\text { Cell } \\
\text { Line }\end{array}$} & \multicolumn{13}{|c|}{ OR gene - hs6M1- } & \multicolumn{2}{|c|}{ HLA } & \multirow{2}{*}{$\begin{array}{c}\text { OR } \\
\text { Haplotype }\end{array}$} \\
\hline & 10 & 15 & 1 & 4P & 3 & 6 & 21 & 20 & 19P & 18 & 17 & 16 & 12 & A & B & \\
\hline $\mathrm{H} 2 \mathrm{LCL}$ & *01 & *01 & *01 & *01 & *01 & *01 & *01 & *03 & *02 & *01 & ${ }^{*} 02$ & *01 & *03 & A3 & B7 & 1 \\
\hline YAR & *01 & ${ }^{*} 01$ & ${ }^{*} 01$ & ${ }^{*} 01$ & ${ }^{*} 01$ & ${ }^{*} 01$ & ${ }^{*} 01$ & ${ }^{*} 03$ & *02 & ${ }^{*} 01$ & ${ }^{*} 02$ & ${ }^{*} 01$ & *03 & A26 & B38 & 1 \\
\hline LG2 & *01 & *01 & *01 & *01 & *01 & *01 & *01 & *01 & *01 & *01 & *01 & *01 & *03 & $\mathrm{A} 2$ & B27 & 2 \\
\hline OLGA-1 & *01 & *01 & *01 & *01 & *01 & *01 & *01 & *05 & *01 & *01 & *03 & *01 & *01 & A31 & B62 & 3 \\
\hline OLGA-2 & *01 & *01 & *01 & ${ }^{*} 02$ & ${ }^{*} 02$ & *02 & $* 03$ & ${ }^{*} 07$ & *01 & *01 & *03 & *01 & *04 & A31 & B62 & 4 \\
\hline SA-1 & *01 & *01 & *01 & *01 & *01 & *01 & *02 & *05 & *02 & *01 & *02 & *01 & *03 & A24 & B7 & 5 \\
\hline SA-2 & *01 & *01 & *01 & *01 & *02 & *02 & *02 & *06 & *01 & *01 & *02 & *01 & *02 & A24 & B7 & 6 \\
\hline BM28.7 & *01 & *01 & *01 & *05 & *02 & *02 & *01 & *01 & *01 & *01 & *01 & *02 & *01 & A1 & B35 & 7 \\
\hline BM19.7 & ${ }^{*} 01$ & ${ }^{*} 01$ & ${ }^{*} 02$ & *05 & ${ }^{*} 02$ & ${ }^{*} 02$ & $*^{*} 01$ & *03 & *02 & *01 & *05 & ${ }^{*} 03$ & ${ }^{*} 02$ & A2 & B13 & 8 \\
\hline WT51-1 & *01 & ${ }^{*} 02$ & *01 & *03 & *03 & *03 & *01 & *02 & *01 & *01 & ${ }^{*} 02$ & *01 & *01 & A23 & B65 & 9 \\
\hline WT51-2 & *01 & *02 & *01 & ${ }^{*} 03$ & *03 & *03 & *01 & ${ }^{*} 02$ & *01 & *01 & ${ }^{*} 02$ & *01 & *04 & A23 & B65 & 10 \\
\hline KR3598-1 & ${ }^{*} 02$ & *01 & *01 & ${ }^{*} 01$ & ${ }^{*} 02$ & *01 & $* 01$ & *03 & *02 & ${ }^{*} 02$ & ${ }^{*} 03$ & *01 & *02 & $\mathrm{A} 2$ & B44 & 11 \\
\hline KR3598-2 & ${ }^{*} 02$ & *01 & *01 & ${ }^{*} 02$ & ${ }^{*} 02$ & ${ }^{*} 02$ & *01 & *04 & *01 & *02 & *03 & *01 & *03 & $\mathrm{A} 2$ & B44 & 12 \\
\hline AMAI & *01 & *03 & *01 & *04 & *04 & *02 & *04 & *01 & *01 & *01 & *04 & *03 & *01 & A68 & B53 & 13 \\
\hline Number of alleles & 2 & 3 & 2 & 5 & 4 & 3 & 4 & 7 & 2 & 2 & 5 & 3 & 4 & & & \\
\hline
\end{tabular}

Note. In the case of the cell lines OLGA, SA, WT51, and KR3598, respectively, the two deducted haplotypes are indicated. However, only in the case of WT51 can an allele of a given OR gene be assigned to one of these haplotypes with certainty.

variability of the $H L A-A$ gene in the cell line panel. The OR genes on chromosomes 7, 17, and 19 showed three, four, and two alleles and were therefore comparable with the HLA-linked OR loci. The allele definitions were not always unambiguous because of the presence in some of the cell lines of two alleles for a given locus. While this could be expected in our study for the nonHLA-linked genes, we had anticipated that the use of HLA-homozygous typing cells or hemizygous cell lines (BM19.7 and BM28.7 are reciprocal HLA haplotype loss mutants derived from the same maternal cell line) would circumvent this problem. Because of this complication, the allele designations are in some cases only tentative.

\section{OR Haplotypes}

The analysis given here allowed us also to define haplotypes of HLA-linked OR genes extending over a distance of nearly $2000 \mathrm{~kb}$, from $h s 6 \mathrm{M} 1-10$ to $h s 6 \mathrm{M} 1-12$ (Table 2). A minimum of 13 different OR haplotypes could be deduced. Two cell lines (H2LCL and YAR) shared alleles for all HLA-linked OR loci investigated, although they exhibited distinct HLA class I haplotypes. The OR haplotypes of all other cell lines differed, and in the case of OLGA, SA, WT51, and KR3598, even the paternal and maternal haplotypes were distinguishable. However, certain combinations of neighboring alleles were conserved between several of the cell lines. For example, with the exception of the hs6M1-20 and -21 loci, one haplotype of SA was identical to that of H2LCL and YAR, and the BM19.7 and BM28.7 cell lines had the alleles of $h s 6 M 1-4 P,-3,-6$, and -21 loci in common, while one of the OLGA and one of the KR3598 haplotypes, respectively, shared the alleles of $h s 6 \mathrm{M} 1-15,-1,-4 P,-3$, and -6 . The OR haplotypes of the cell lines WT51 and AMAI appeared to be the most divergent among the set of cell lines employed. However, even in these cases, the alleles of the closely linked OR loci hs6M1-20 (only AMAI), -19P, and -18 were observed at least partly also in LG2, OLGA (both haplotypes), SA (one haplotype), and BM28.7. The three different $H L A-A 2$ bearing haplotypes were associated with four different haplotypes of HLAlinked OR genes (Table 2).

\section{DISCUSSION}

Allelic variability of human M-OR genes has been predicted (Mombaerts 1999b) but not conclusively shown. Therefore, the demonstration of OR gene variability reported here is the first such systematic study and provides clear-cut evidence that sequence polymorphisms are a regular feature of these genes, irrespective of their chromosomal location. As HLA class I and II genes are characterized by extreme genetic polymorphism, with far more than 100 alleles for each of the HLA-A and -B genes, respectively (Bodmer et al. 1999), OR genes in close linkage to the HLA complex may be expected to exhibit pronounced variability as well, as demonstrated for the GABBR1 locus (Peters et al. 1998). Our finding that three of the HLA-linked OR genes analyzed exhibit alleles that are likely to be either functional or nonfunctinal, respectively, has also been foreseen (Mombaerts 1999b). The type of polymorphism observed by us is qualitatively different from that found by Trask and coworkers (1998). They described a 36-kb sequence containing three OR genes, one of them potentially functional, that may be in- 
serted at various subtelomeric chromosomal sites, leading to a variable number of OR loci in individual genomes.

The major and minor M-OR gene clusters are separated from HLA-F by a distance of $135 \mathrm{~kb}$ and $\sim 2000 \mathrm{~kb}$, respectively (Fig. 1; for details, see Younger et al. 2000). Of the $34 \mathrm{M}$-OR genes within the two clusters, 17 $(50 \%)$ are potentially functional at least in some of the haplotypes, while $50 \%$ are pseudogenes with unclear functional status. Another study (Rouquier et al. 1998b) arrived at an estimate of $72 \%$ pseudogenes among the M-OR loci within the human genome, while the OR gene cluster in the human chromosomal region $17 \mathrm{p} 13.3$ contained nearly double as many genes with ORF than with pseudogenes (Glusman et al. 2000). The frequency of potentially functional genes is greater in the major than in the minor HLA-linked cluster $(14 / 25[56 \%]$ vs. 3/9 [33\%]). However, these numbers are likely to be underestimates. First, inspection of further alleles of the pseudogenes may yield variants with ORF; second, the search of EST databases has revealed that at least the $h s 6 \mathrm{M} 1-14 \mathrm{P}$ and $-24 P$ genes are transcribed (Younger et al. 2000). Finally, the expression of functional chemokine receptors despite loss of the first two transmembrane domains (Ling et al. 1999) may indicate that OR genes lacking start codons (e.g., hs6M1-14P) could be expressed also at the protein level by using an alternative ATG start codon at the beginning of extracellular domain 2. In this context, the finding of two ESTs splicing to this methionine in the hs6M1-16 gene is remarkable, resulting in a possibly functional, N-terminally truncated OR gene product (Younger et al. 2000). Similarly, it could be that the $h s 6 M 1-17^{*} 05$ allele, which exhibits a stop codon in the first cytoplasmic domain (Table 1), is in fact functional.

However, this situation is likely to be different for the $h s 6 M 1-4 P^{*} 01$ and $-19 P^{*} 01$ alleles (Table 1). In the first case, the stop codon occurs within the third extracellular domain, while $h s 6 \mathrm{M} 1-19 \mathrm{P}^{*} 01$ exhibits a sizable deletion, also within this domain. In either case, the resulting C-terminally truncated protein is highly likely to be nonfunctional. The frequency of the two nonfunctional alleles, respectively, is quite high among the cell lines analyzed: In both cases, more than half of the chromosome $6 \mathrm{~s}$ carried these sequence polymorphisms. This is in contrast to the $h s 6 \mathrm{M} 1-17^{*} 05$ allele, which occurred only in the HLA hemizygous BM19.7 cell line. The $h s 6 M 1-19 P^{*} 01$ allele must have been derived from the potentially functional hs6M1$19 P^{*} 02$ allele, as it appears very unlikely that an insertion of $16 \mathrm{bp}$, at the correct position, into the *01 allele would have occurred to restore the * 02 allele. Therefore, the hs6M1-19P gene is an example of pseudogenization within the human species, not just between species as described by Rouquier and colleagues (1998a). Clearly, more work is needed to evaluate the frequency with which comparable events occur in further individuals and other OR genes.

The allelic differences observed for nearly all of the OR genes studied here could affect their interaction with extracellular ligands or intracellular proteins of the signal transduction cascade. By comparing sequence features of 197 OR from various species, Pilpel and Lancet (1999) have found that the regions of highest sequence diversity among these OR are located within the transmembrane regions $3,4,5$, and 6 , although the extracellular regions 2 and, in particular, 4 (EC1 and EC3 in their nomenclature) are also highly variable. However, in the set of HLA-linked OR studied here, EC4 exhibits no variability at all (Fig. 2), and only a silent polymorphism is observed within the TM7 region in hs6M1-15 (Table 1). The exchanges in the transmembrane regions could have functional consequences, as it has been suggested that these domains are involved in ligand binding (Buck and Axel 1991; Pilpel and Lancet 1999). Even conservative AA exchanges like the Val159lle polymorphism in TM4 of hs6M1-20 might well give rise to changes in ligand specificity, as this has been shown for a similar AA exchange (Val206Ile, in TM5 of a murine OR), which leads to preferential binding of either octanal or heptanal (Krautwurst et al. 1998). The Arg138Trp polymorphism in the hs6M1-17 gene can serve as an example for several of the nonconservative exchanges that are even more likely to result in a functional difference. Furthermore, M-OR genes contain intracellular AAsequences that are highly conserved and are thought to be important for receptor function, possibly G-protein binding (Hedin et al. 1993). This is exemplified by the ORIC1, ORIC2, and ORIC3 sequence motifs in cytoplasmic loops CP1, 2, and 3 (Pilpel and Lancet 1999). The hs6M1-17 gene exhibits changes in the first two of these motifs (in CP1, a Gln55His replacement in nearly all alleles, and in CP2, an Arg121Cys polymorphism), while the hs6M1-10 and hs6M1-21 genes were polymorphic in CP3 (Table 1).

The task of reliably distinguishing thousands of odors might best be accomplished by OR that are not only numerous but also polymorphic. However, in the absence of any data on ligand specificity for the HLAlinked OR, it is clearly premature to embark on speculations regarding the possible importance of AA replacements within any of the OR domains. Only those OR with potentially functional and nonfunctional alleles like $h s 6 \mathrm{M} 1-4 \mathrm{P}$ allow us to predict that individuals who are homozygous for the $h s 6 M 1-4 P^{*} 01$ allele may exhibit a specific anosmia. It is evident that this olfactory deficit offers interesting opportunities to correlate behavioral features with genetic polymorphisms (see also Mombaerts 1999b). Persons heterozygous for an active and an inactive allele might exhibit altered 
odorant detection thresholds than people homozygous for the active allele. It is, however, possible that the situation will not be as simple, as the specificities of different OR proteins might overlap, so that an inactive OR could be compensated for by related receptors, possibly even within the same OR cluster (Malnic et al. 1999; Tsuboi et al. 1999).

For the first time, the data presented here allow also the definition of haplotypes for any of the known OR gene clusters (Table 2). Despite limited OR polymorphism, when compared to HLA class I loci, it was possible to demonstrate the presence of 13 distinct haplotypes of HLA-linked OR genes among the cell lines analyzed, which represent 18 different chromosome $6 \mathrm{~s}$. As pointed out before, the number of haplotypes is higher than that of the HLA class I haplotypes within the cell line panel. Despite the consanguineous origin of most of the cell lines employed here, it can not be excluded that some are in fact not HLA class I homozygous, possibly leading to an increase in OR gene polymorphism, as well. Obviously, candidates for this constellation are OLGA, SA, WT51, and KR3598, which are characterized by one (WT51) to six (OLGA) HLA-linked OR loci with two alleles. These numbers are subject to further changes when all HLA-linked OR genes will have been discovered and additional polymorphisms detected. The analysis of the OR gene haplotypes reveals also that the cell lines H2LCL and YAR share identical OR alleles for all loci analyzed, with the sole exception of the hs19M1-4 gene, where H2LCL but not YAR exhibits heterozygosity. YAR is of Jewish origin, while we could not trace the origin of H2LCL (described to be of Caucasian origin) with certainty.

It is currently unclear whether the sharing of blocks of alleles by different HLA-linked OR haplotypes (Table 2), which to some extent reminds us of the organization of the HLA class I region into three genomic blocks (reviewed by Kulski et al. 2000), will be observed also after further individuals have been analyzed. The CEPH families provide a good opportunity for such studies: They have been HLA typed, and extended haplotypes caused by linkage disequilibrium are known to exist between the HLA-A and HFE genes in these families (Malfroy et al. 1997). As MHC class I and/or linked loci are involved in shaping individual-specific odors and odor preferences (Wedekind et al. 1995; Wedekind and Füri 1997; Penn and Potts 1998b; Milinski and Wedekind 2000), further research in this area might also seek to provide evidence in favor of or against a functional connection between linked HLA and OR genes.

\section{METHODS}

\section{Cell Culture}

Cell lines were derived from different donors, representing different HLA haplotypes and different ethnic origins. Eight of the 10 cell lines were HLA homozygous, whereas two (BM19.7, BM28.7) were HLA hemizygous (Ziegler et al. 1985; Volz et al. 1992). All cell lines were grown in RPMI 1640 medium containing antibiotics and $10 \%$ fetal calf serum.

\section{Polymerase Chain Reaction}

We designed two to three pairs of primers for the respective genes ( $h s 6 M 1-1=$ AL022727; hs6M1-2P = AL022727, AJ132194; hs6M1-3 = AL022727; hs6M1-4P = AL022727; hs6M1$5 P=\mathrm{AL022727} ;$ hs6M1-6 = AL022727; hs6M1-7P = AL022727; hs6M1-8P = CAB55431; hs6M1-10 = Z98744; hs6M1$12=$ AL031983, AC006137; hs6M1-13P = AL031983, AC006137; hs6M1-15 = AL035402; hs6M1-16 = AL035542, AC004178; hs6M1-17 = AL035542; hs6M1-18 = AL035542; hs6M1-19P = AL035542; hs6M1-20 = AL035542; hs6M1$21=\mathrm{AL} 096770 ;$ hs6M1-23P = AL050339; hs6M1$24 P=\mathrm{AL} 050339 ;$ hs6M1-25P = AL050339; hs6M1$26 P=\mathrm{AL} 035402 ;$ hs 7M1-1 = AC004853; hs 17M1$20=$ AC002085; and hs19M1-4 = AC002988), resulting in overlapping PCR products. Because two different sequencing strategies were employed, PCR primers were generated with or without M13 tail. Specificity of the primers was tested by aligning all known ORs.

PCR primers were generated with M13 for/rev tails to sequence the PCR products with fluorescence-labeled M13 primers. For PCR, 100 ng template DNA, 10 pmole of each primer, $0.2 \mathrm{mM}$ of each dNTP (Pharmacia Biotech), $1 \mathrm{U}$ Ampli-Taq DNA-polymerase (Perkin-Elmer), and $1 \times$ buffer (Perkin Elmer) were used in a final volume of $20 \mu \mathrm{L}$.

PCR primers without M13 tail were used for subsequent sequencing with the ABI Prism cycle sequencing kit. For PCR, $\sim 50 \mathrm{ng}$ template DNA, $100 \mathrm{ng}$ of each primer, $2 \mathrm{mM}$ of each dNTP (GIBCO), 1-2 mM MgCl $2,1 \mathrm{U}$ Taq polymerase (GIBCO) and $1 \times \mathrm{KCl}$ buffer was used in a final volume of $50 \mu \mathrm{L}$. The primers and PCR conditions are given in Table 3.

\section{Cycle Sequencing}

We used two different sequencing strategies. Sequence analysis was performed either using the Thermo Sequenase fluorescent labeled primer cycle sequencing kit with 7-deaza-dGTP (Amersham Pharmacia Biotech) employing 150 ng DNA for 1 kb, 1 pmol primer (M13for: 5'-TGTAAAACGACGGCCAGT; M13rev: 5'-CAGGAAACAGCTATGACC), $0.25 \mu \mathrm{L}$ DMSO and $2 \mu \mathrm{L}$ reaction mix in a final volume of $7 \mu \mathrm{L}\left(27\right.$ cycles; $95^{\circ} \mathrm{C}$ for $4 \mathrm{~min}, 95^{\circ} \mathrm{C}$ for $15 \mathrm{sec}, 56^{\circ} \mathrm{C}$ for $15 \mathrm{sec}, 70^{\circ} \mathrm{C}$ for $15 \mathrm{sec}$ ) followed by analysis on $4 \%$ polyacrylamide gels with a LI COR sequencer (MWG Biotech) or by employing $3.2 \mathrm{pmol}$ of each of the PCR primers using the ABI Prism cycle sequencing kit. In this case, the DNA products were electrophoresed through $6 \%$ polyacrylamide gels in an ABI semiautomatic sequencer.

\section{Restriction Analysis}

All nucleotide substitutions observed by ABI cycle sequencing were subsequently confirmed by restriction analysis. Sequences of the two alternate alleles were restriction mapped using the tacg (v2.38) program at University of California Irvine. Restriction enzymes detecting the polymorphic site were selected and used to digest $10 \mu \mathrm{L}$ of the PCR products generated from the panel of DNAs in a $50-\mu \mathrm{L}$ reaction overnight. Digestion products were then analyzed on a $2.5 \%$ agarose gel.

\section{Cloning}

Most of the genes showing heterozygous positions in different 
Table 3. PCR Primers and PCR Conditions

\begin{tabular}{|c|c|c|c|c|}
\hline \multicolumn{5}{|c|}{ 1.Primers with M13 tail and PCR-parameters } \\
\hline Gene-Name & Primer-Name & Sequence & $\begin{array}{l}\text { Temp } \\
{ }^{\circ} \mathrm{C}\end{array}$ & DMSO \\
\hline hs6M1-1 & $\begin{array}{l}\text { OR1-4for } \\
\text { OR1-615rev }\end{array}$ & $\begin{array}{l}\text { TGTAAAACGACGGCCAGTATAAACAAACATTGATTGCT } \\
\text { CAGGAAACAGCTATGACCCATGACAACTTGAGAAGTGC }\end{array}$ & 50 & $+2 \%$ \\
\hline hs6M1-1 & $\begin{array}{l}\text { OR1-477for } \\
\text { OR1-1064rev }\end{array}$ & $\begin{array}{l}\text { TGTAAAACGACGGCCAGTAATTATTGGTTCTGCCTAAG } \\
\text { CAGGAAACAGCTATGACCTGAGTTCAAAGGTCATTACC }\end{array}$ & 57 & $+2 \%$ \\
\hline hs6M1-2P & $\begin{array}{l}\text { OR2-77F } \\
\text { OR2-764R }\end{array}$ & $\begin{array}{l}\text { TGTAAAACGACGGCCAGTICTGACCCCAGGTTACTGC } \\
\text { CAGGAAACAGCTATGACCGAACCCTTTTCACCACAGGC }\end{array}$ & 60 & \\
\hline hs6M1-2P & $\begin{array}{l}\text { OR2-683F } \\
\text { OR2-1231R }\end{array}$ & $\begin{array}{l}\text { TGTAAAACGACGGCCAGTACTGCCACATTACAATTGCC } \\
\text { CAGGAAACAGCTATGACCTTGCAAGAACATGTAAAGCG }\end{array}$ & 55 & \\
\hline hs6M1-3 & $\begin{array}{l}\text { OR3-27for } \\
\text { OR3-711rev }\end{array}$ & $\begin{array}{l}\text { TGTAAAACGACGGCCAGTGTGTGCTGATATTTTTGGAT } \\
\text { CAGGAAACAGCTATGACCAATATGGAGCTTGTGATCAT }\end{array}$ & 54 & \\
\hline hs6M1-3 & $\begin{array}{l}\text { OR3-576for } \\
\text { OR3-1127rev }\end{array}$ & $\begin{array}{l}\text { TGTAAAACGACGGCCAGTAACTCAGCACTTCATTCCTC } \\
\text { CAGGAAACAGCTATGACCGTGCTAACAGAGTGCGTGAA }\end{array}$ & 64 & \\
\hline hs6M1-4P & $\begin{array}{l}\text { OR4-446f } \\
\text { OR4-1274r }\end{array}$ & $\begin{array}{l}\text { TGTAAAACGACGGCCAGTTACAGTTCAACTTTACTTTG } \\
\text { CAGGAAACAGCTATGACCAGAACAAAATGGTACTAATC }\end{array}$ & 56 & \\
\hline hs6M1-4P & $\begin{array}{l}\text { OR4-48 } \\
\text { OR4-653 }\end{array}$ & $\begin{array}{l}\text { TGTAAAACGACGGCCAGTATTGGGATACTTIITCTCC } \\
\text { CAGGAAACAGCTATGACCGGCGATGTCTACATAGGGGT }\end{array}$ & 61 & \\
\hline hS6M1-5P & $\begin{array}{l}\text { OR5-419f } \\
\text { OR5-1231r }\end{array}$ & $\begin{array}{l}\text { TGTAAAACGACGGCCAGTGGTCAGTCTCTGGGGTGTGG } \\
\text { CAGGAAACAGCTATGACCGTTACCAGGATCTCCACGAC }\end{array}$ & 60 & \\
\hline hs6M1-6 & $\begin{array}{l}\text { OR6-47F } \\
\text { OR6-699R }\end{array}$ & $\begin{array}{l}\text { TGTAAAACGACGGCCAGTAAGTGAGCGGTTGACAATGC } \\
\text { CAGGAAACAGCTATGACCGGTCAGCTCATTTGCATGGG }\end{array}$ & 64 & $+2 \%$ \\
\hline hs6M1-6 & $\begin{array}{l}\text { OR6-621F } \\
\text { OR6-1112Rn }\end{array}$ & $\begin{array}{l}\text { TGTAAAACGACGGCCAGTTACCCCTTTGTGGACATCGC } \\
\text { CAGGAAACAGCTATGACCGGAAACCACCTTTCAAGATG }\end{array}$ & 60 & $+2 \%$ \\
\hline hs6M1-7P & $\begin{array}{l}\text { OR7-85F } \\
\text { OR7-726R }\end{array}$ & $\begin{array}{l}\text { TGTAAAACGACGGCCAGTTCATATACCACCCGTCTTCC } \\
\text { CAGGAAACAGCTATGACCGAGAGCTGAATCAGAGCTGG }\end{array}$ & 60 & $+2 \%$ \\
\hline hs6M1-7P & $\begin{array}{l}\text { OR7-643F } \\
\text { OR7-1280R }\end{array}$ & $\begin{array}{l}\text { TGTAAAACGACGGCCAGTCCCAGTCTCTGATCCAGTCC } \\
\text { CAGGAAACAGCTATGACCTATGAAGAATTTAAGGGCCC }\end{array}$ & 67 & \\
\hline hs6M1-10 & $\begin{array}{l}\text { OL-AE } 800 \mathrm{f} \\
\text { OL-AE } 1525 \mathrm{r}\end{array}$ & $\begin{array}{l}\text { TGTAAAACGACGGCCAGTTTTTCACATTATTAATTGG } \\
\text { CAGGAAACAGCTATGACCATGAAGAATAGTTCAGCCTC }\end{array}$ & 52 & \\
\hline hs6M1-10 & $\begin{array}{l}\text { OL-AE } 1446 \mathrm{f} \\
\text { OI-AE } 2164 \mathrm{r}\end{array}$ & $\begin{array}{l}\text { TGTAAAACGACGGCCAGTIGGTCACAAAGAAGTGGATC } \\
\text { CAGGAAACAGCTATGACCTGATTTCTGGATCAGAAAGG }\end{array}$ & 52 & \\
\hline hs6-M1-15 & $\begin{array}{l}\text { OR15-403f } \\
\text { OR15-1029r }\end{array}$ & $\begin{array}{l}\text { TGTAAAACGACGGCCAGTTCTCCCTCCTCCTTCTCCTC } \\
\text { CAGGAAACAGCTATGACCATCCAGAATGTTGTTTCCAC }\end{array}$ & 60 & \\
\hline$h s 6-M 1-15$ & $\begin{array}{l}\text { OR15-847f } \\
\text { OR15-1708r }\end{array}$ & $\begin{array}{l}\text { TGTAAAACGACGGCCAGTCTCAGTTGAGTGCCTTCTCC } \\
\text { CAGGAAACAGCTATGACCATTTGTGTTTATTTCAAGC }\end{array}$ & 60 & \\
\hline hs6M1-16 & $\begin{array}{l}\text { OR11-204f } \\
\text { OR11-1091r }\end{array}$ & $\begin{array}{l}\text { TGTAAAACGACGGCCAGTGATCAGAAGGAACAGGGAAC } \\
\text { CAGGAAACAGCTATGACCCCCAAAGGCCTTTCTCCATG }\end{array}$ & 58 & \\
\hline hs6M1-16 & $\begin{array}{l}\text { Fat11 1038 } \\
\text { Fat11 B }\end{array}$ & $\begin{array}{l}\text { TGTAAAACGACGGCCAGTCAGCTCTAATTCGACTCTCC } \\
\text { CAGGAAACAGCTATGACCGAAATCTATAGGAGTGATGA }\end{array}$ & 52 & \\
\hline hs6M1-18 & $\begin{array}{l}\text { OR18-108-f } \\
\text { OR18-756-r }\end{array}$ & $\begin{array}{l}\text { TGTAAAACGACGGCCAGTGTTGAGGAAGGAATGACAAC } \\
\text { CAGGAAACAGCTATGACCCATCTACCACAAATCCAGAG }\end{array}$ & 60 & \\
\hline hs6M1-18 & $\begin{array}{l}\text { OR18-606f } \\
\text { OR18-1368r }\end{array}$ & $\begin{array}{l}\text { TGTAAAACGACGGCCAGTGTTCTTTATCTTCGGCTCTC } \\
\text { CAGGAAACAGCTATGACCTTTCATTTTAGTATAACTG }\end{array}$ & 53 & \\
\hline hs6M1-24P & $\begin{array}{l}\text { OR24-r713 } \\
\text { OR24-r1663 }\end{array}$ & $\begin{array}{l}\text { TGTAAAACGACGGCCAGTGTCAAAATTGCATGTGGGGC } \\
\text { CAGGAAACAGCTATGACCACAGTGCTGGGATTACAGGC }\end{array}$ & 60 & \\
\hline hs6M1-25P & $\begin{array}{l}\text { OR25-1222 } \\
\text { OR25-r866 }\end{array}$ & $\begin{array}{l}\text { TGTAAAACGACGGCCAGTGCCCCACCTGGAAAAGATCC } \\
\text { CAGGAAACAGCTATGACCCCACATGTCCCCAGGCCTा }\end{array}$ & 62 & \\
\hline$h s 6 M 1-26 P$ & $\begin{array}{l}\text { OR26-f53 } \\
\text { OR26-r573 }\end{array}$ & $\begin{array}{l}\text { TGTAAAACGACGGCCAGTCCATCTGCAAACACTTGAGG } \\
\text { CAGGAAACAGCTATGACCATACAAAAAGACAAGAAGCC }\end{array}$ & 60 & \\
\hline
\end{tabular}

\begin{tabular}{|c|c|c|c|c|}
\hline Gene-Name & $\begin{array}{l}\text { Primer- } \\
\text { Name }\end{array}$ & Sequence & $\begin{array}{l}\text { Temp } \\
{ }^{\circ} \mathrm{C}\end{array}$ & $\begin{array}{r}\mathrm{MgCl}_{2} \\
{[\mathrm{mM}]}\end{array}$ \\
\hline hs6M1-8P & $\begin{array}{l}\text { OLFR8pF } \\
\text { OR8pR }\end{array}$ & $\begin{array}{l}\text { GTTGGCTGTGATGGCCTATG } \\
\text { GATGGGAAGGTTAAGGCTGG }\end{array}$ & 62 & 1 \\
\hline hs6M1-12 & $\begin{array}{l}\text { OLFR12F1 } \\
\text { OLFR12R1 }\end{array}$ & $\begin{array}{l}\text { TTACTACATTTCAGTCGCTGTC } \\
\text { GTGCTGAGGATTAACTCTGC }\end{array}$ & 62 & 1,5 \\
\hline hs6M1-12 & $\begin{array}{l}\text { OLFR12F2 } \\
\text { OLFR12R2 }\end{array}$ & $\begin{array}{l}\text { GTGACCACAGTGAGATGGG } \\
\text { ATCAGCTTCCTGGACTGCTC }\end{array}$ & 60 & 1 \\
\hline hs6M1-12 & $\begin{array}{l}\text { OLFR12F3 } \\
\text { OLFR12R3 }\end{array}$ & $\begin{array}{l}\text { CTGTCAAGAGGATGCACTCAG } \\
\text { AGACAGGTTGAATCACACTGG }\end{array}$ & 62 & 1,5 \\
\hline hS6M1-13P & $\begin{array}{l}\text { OLFR13F1 } \\
\text { OLFR13R1 }\end{array}$ & $\begin{array}{l}\text { CTTGGGAGCTCAAACTTGTTC } \\
\text { CACCTCCTACAATGAGATCCAG }\end{array}$ & 62 & 1,5 \\
\hline hs6M1-13P & $\begin{array}{l}\text { OLFR13F2 } \\
\text { OLFR13R2 }\end{array}$ & $\begin{array}{l}\text { GAGGCACAGCCAAGATGAAG } \\
\text { GGACCTCTGTTTCACCATAAGTTG }\end{array}$ & 62 & 1 \\
\hline hS6M1-13P & $\begin{array}{l}\text { OLFR13F3 } \\
\text { OLFR13R3 }\end{array}$ & $\begin{array}{l}\text { GCAGCCCAGTAAGATGATGG } \\
\text { AACACTCACCTACTGGGACCTC }\end{array}$ & 62 & 1 \\
\hline hs6M1-17 & $\begin{array}{l}\text { OR17-F } \\
\text { OR17-R }\end{array}$ & $\begin{array}{l}\text { TTGTCTTTCTGACAGGCTGG } \\
\text { AGGGAGATCTAGTGCTGCGA }\end{array}$ & 60 & 2 \\
\hline hS6M1-19P & $\begin{array}{l}\text { OLFR19pF } \\
\text { OLFR19pR }\end{array}$ & $\begin{array}{l}\text { ATGAAGTGGGAGGCACAAGT } \\
\text { GCTGCACTCCCTAATGACCT }\end{array}$ & 62 & 1,5 \\
\hline hS6M1-19P & $\begin{array}{l}\text { OLFR19.1F } \\
\text { OLFR19.1R }\end{array}$ & $\begin{array}{l}\text { TTTAATCCAGTTCCCTCTGTTG } \\
\text { ATTCTTTAGCATGCTCCGC }\end{array}$ & 60 & 1,5 \\
\hline hs6M1-19P & $\begin{array}{l}\text { OLFR19.2F } \\
\text { OLFR19.2R }\end{array}$ & $\begin{array}{l}\text { AGCAATGGCTTCACATCACAG } \\
\text { CCTGGACATCTGCTACTCCA }\end{array}$ & 60 & 1 \\
\hline hs6M1-19P & $\begin{array}{l}\text { OLFR19.3F } \\
\text { OLFR19.3R }\end{array}$ & $\begin{array}{l}\text { GGCTTATGCATCCCAAGAA } \\
\text { TCTGAGTCGGAAGGATTCTGA }\end{array}$ & 60 & 1,5 \\
\hline hs6M1-20 & $\begin{array}{l}\text { OR20-F } \\
\text { Or20-R }\end{array}$ & $\begin{array}{l}\text { TCCCCAGAAGAAAGAAATACGT } \\
\text { GGCTAGTGTCTTGCATTTTCAA }\end{array}$ & 60 & 1 \\
\hline hs6M1-21 & $\begin{array}{l}\text { OLFR21.1F } \\
\text { OLFR21.1R }\end{array}$ & $\begin{array}{l}\text { TTCTCTITGCCCAATTCCTG } \\
\text { TATGCCATTGCTGCCAGTAG }\end{array}$ & 60 & 1 \\
\hline hs6M1-21 & $\begin{array}{l}\text { OLFR21.2F } \\
\text { OLFR21.2R }\end{array}$ & $\begin{array}{l}\text { GGGGTGTGTGGTTCAACTTT } \\
\text { CGTCTTCCCTCTGAGGACTG }\end{array}$ & 62 & 1 \\
\hline hs6M1-21 & $\begin{array}{l}\text { OLFR21.3F } \\
\text { OLFR21.3R }\end{array}$ & $\begin{array}{l}\text { CATTGGTTGGACTCCTTTCC } \\
\text { TCAATATCTGTCCCAACATTGC }\end{array}$ & 60 & 1,5 \\
\hline hs6M1-23P & $\begin{array}{l}\text { OLFR23pF } \\
\text { OLFR23pR }\end{array}$ & $\begin{array}{l}\text { CTTGTGGTCATCTCCTGGGT } \\
\text { AGCCACAGCAATGAAACCAT }\end{array}$ & 60 & 1,5 \\
\hline hs7M1-2 & $\begin{array}{l}\text { OLFR 7F1 } \\
\text { OLFR 7R1 }\end{array}$ & $\begin{array}{l}\text { TAGGGCTGGCTGGCATGTA } \\
\text { ACAGCTCTGGAATGGGATGG }\end{array}$ & 65 & 1,5 \\
\hline hs7M1-2 & $\begin{array}{l}\text { OLFR7F3 } \\
\text { OLFR 7R3 }\end{array}$ & $\begin{array}{l}\text { GTGGACACCTCCTCCAATGA } \\
\text { CTGGGTGGAGAACACTGAGG }\end{array}$ & 64 & 1,5 \\
\hline hs7M1-2 & $\begin{array}{l}\text { OLFR 7F1 } \\
\text { OLFR 7R3 }\end{array}$ & $\begin{array}{l}\text { TAGGGCTGGCTGGCATGTA } \\
\text { CTGGGTGGAGAACACTGAGG }\end{array}$ & 62 & 1,5 \\
\hline hs17M1-20 & $\begin{array}{l}\text { OLFR 17F1 } \\
\text { OLFR 17R1 }\end{array}$ & $\begin{array}{l}\text { ACACCTCATCCTGCTTCTGC } \\
\text { ATGGCCAGATAGCGGTCATA }\end{array}$ & 64 & 1,5 \\
\hline hs17M1-20 & $\begin{array}{l}\text { OLFR 17F2 } \\
\text { OLFR 17R2 }\end{array}$ & $\begin{array}{l}\text { CCTATAAGGCCTGCCTCTCC } \\
\text { CATAGAAGATGCCCACCACA }\end{array}$ & 64 & 1,5 \\
\hline hs17M1-20 & $\begin{array}{l}\text { OLFR 17F3 } \\
\text { OLFR 17R3 }\end{array}$ & $\begin{array}{l}\text { ACTGTGTCCTATGCCCATGT } \\
\text { GTGCTGTTGGTGAGAAGCTG }\end{array}$ & 62 & 1,5 \\
\hline hs 19M1-4 & $\begin{array}{l}\text { OLFR 19F1 } \\
\text { OLFR 19R1 }\end{array}$ & $\begin{array}{l}\text { GGCACAGAGTGAGAGACCC } \\
\text { GATCATAGGCCATCACAGCC }\end{array}$ & 58 & 1 \\
\hline hs19M1-4 & $\begin{array}{l}\text { OLFR 19F2 } \\
\text { OLFR 19R2 }\end{array}$ & $\begin{array}{l}\text { GAGTCATCACCTATGCAGGCT } \\
\text { TGCCTTGTACTTCCCCTGAG }\end{array}$ & 60 & 1 \\
\hline hs19M1-4 & $\begin{array}{l}\text { OLFR 19F3 } \\
\text { OLFR 19R3 }\end{array}$ & $\begin{array}{l}\text { TGGGGATCCTTTGCTCTTAC } \\
\text { GCAAATTCCACTTTCACAACC }\end{array}$ & 58 & 2 \\
\hline
\end{tabular}

PCR fragments after sequencing with fluorescence-labeled M13 primers were amplified by PCR with both exterior primers to a DNA fragment encoding the full-length receptor. The fragments were cloned into vector pCR II-TOPO (Invitrogen) according to the manufacturer's recommendations and grown overnight in $200 \mu \mathrm{L} \mathrm{LB}$ medium with ampicillin. The full-length insert was recovered by PCR with the same primers and sequenced to determine the respective alleles of the genes.

Nomenclature

In the absence of an official OR nomenclature, we have as-

\section{Genome Research}

www.genome.org 
signed unique designations to describe OR genes unambiguously (Younger et al. 2000; Ziegler et al. 2000a). The names identify the species (hs for humans [Homo sapiens], $\mathrm{mm}$ for mouse [Mus musculus]), followed by a number representing the chromosome (e.g. "6" for chromosome 6), then a letter and a number indicating the OR type and subtype, ("M1" for MOE subtype 1; "V1" and "V2" for the two VNO subtypes). This descriptive information is followed by a dash (-) and an arbitrary but unique gene identification number. Pseudogenes are indicated with a "P" (e.g., hs6M1-4P). Following the HLA nomenclature, OR alleles are indicated by an asterisk $\left(^{*}\right)$ and a unique allele number ( $\left.h s 6 \mathrm{M} 1-20^{*} 07\right)$. The allele ${ }^{*} 01$ was used here to indicate the allele in the originally sequenced genomic DNA. Furthermore, OR genes and proteins may be referred to as "M-OR", "V1-OR," or "V2-OR" depending on the type and subtype they belong to. This proposal for a consistent OR gene nomenclature was discussed and submitted to the HUGO/GDB Nomenclature Committee for consideration.

\section{ACKNOWLEDGMENTS}

We thank the Volkswagen Foundation (grant I/72 740 to A.Z. and J.T.) and the Wellcome Trust (S.B.) for financial support. R.M.Y. was supported by a studentship of the UK Medical Research Council. A.Z. and S.B. thank the Wellcome Trust for a Biomedical Research Collaboration Grant.

The publication costs of this article were defrayed in part by payment of page charges. This article must therefore be hereby marked "advertisement" in accordance with 18 USC section 1734 solely to indicate this fact.

\section{REFERENCES}

Beauchamp, G.K. and Yamazaki, K. 1997. HLA and mate selection in humans: Commentary. Am. J. Hum. Genet. 61: 494-496.

Bodmer, J.G., Marsh, S.G., Albert, E.D., Bodmer, W.F., Bontrop, R.E., Dupont, B., Erlich, H.A., Hansen, J.A., Mach, B., Mayr, W.R., et al. 1999. Nomenclature for factors of the HLA system, 1998. Vox Sang 77: 164-191.

Brown, R.E., Roser, B., and Singh, P.B. 1989. Class I and class II regions of the major histocompatibility complex both contribute to individual odors in congenic inbred strains of rats. Behav. Genet. 19: 659-674.

Buck, L. and Axel, R. 1991. A novel multigene family may encode odorant receptors: a molecular basis for odor recognition. Cell 65: $175-187$.

Dulac, C. and Axel, R. 1995. A novel family of genes encoding putative pheromone receptors in mammals. Cell 83: 195-206.

Fan, W., Liu, Y.C., Parimoo, S., and Weissman, S.M. 1995. Olfactory receptor-like genes are located in the human major histocompatibility complex. Genomics 27: 119-123.

Glusman, G., Sosinsky, A., Ben-Asher, E., Avidan, N., Sonkin, D., Bahar, A., Rosenthal, A., Clifton, S., Roe, B., Ferraz, C., et al. 2000. Sequence, structure and evolution of a complete human olfactory receptor cluster. Genomics 63: 227-245.

Gruen, J.R., Nalabolu, S.R., Chu, T.W., Bowlus, C., Fan, W.F., Goei, V.L., Wei, H., Sivakamasundari, R., Liu, Y., Xu, H.X., et al. 1996 A transcription map of the major histocompatibility complex (MHC) class I region. Genomics 36: 70-85.

Hedin, K.E., Duerson, K., and Clapham, D.E. 1993. Specificity of receptor-G protein interactions: searching for the structure behind the signal. Cell Signal 5: 505-518.

Herrada, G. and Dulac, C. 1997. A novel family of putative pheromone receptors in mammals with a topographically organized and sexually dimorphic distribution. Cell 90: 763-773.

Krautwurst, D., Yau, K.W., and Reed, R.R. 1998. Identification of ligands for olfactory receptors by functional expression of a receptor library. Cell 95: 917-926.

Kulski, J.K., Gaudieri, S., and Dawkins, R.L. 2000. Transposable elements and the metamerismatic evolution of the HLA class I region. In Major histocompatibility complex-Evolution, structure, function (ed. M. Kasahara), pp. 158-177. Springer, Tokyo.

Leinders-Zufall, T., Lane, A.P., Puche, A.C., Ma, W., Novotny, M.V., Shipley, M.T., and Zufall, F. 2000. Ultrasensiive pheromone detection by mammalian vomeronasal neurons. Nature 405: 792-796.

Ling, K., Wang, P., Zhao, J., Wu, Y.-L., Cheng, Z.-J., Wu, G.-X., Hu, W., Ma, L., and Pei, G. 1999. Five-transmembrane domains appear sufficient for a $G$ protein-coupled receptor: Functional five-transmembrane domain chemokine receptors. Proc. Natl. Acad. Sci. 96: 7922-7927.

Malfroy, L., Roth, M.P., Carrington, M., Borot, N., Volz, A., Ziegler, A., and Coppin, H. 1997. Heterogeneity in rates of recombination in the $6-\mathrm{Mb}$ region telomeric to the human major histocompatibility complex. Genomics 43: 226-231.

Malnic, B., Hirono, J., Sato, T., and Buck, L.B. 1999. Combinatorial receptor codes for odors. Cell 96: 713-723.

Matsunami, H. and Buck, L.B. 1997. A multigene family encoding a diverse array of putative pheromone receptors in mammals. Cell 90: $775-784$

Milinski, M. and Wedekind, C. 2000. Evidence for MHC-correlated perfume preferences in humans. Behav. Ecol., in press.

Mombaerts, P. 1999a. Molecular biology of odorant receptors in vertebrates. Annu. Rev. Neurosci. 22: 487-509.

- 1999b. Odorant receptor genes in humans. Curr. Opin. Genet. Dev. 9: 315-320.

Naruse, T.K., Nose, Y., Ando, R., Araki, N., Shigenari, A., Ando, A., Ishihara, M., Kagiya, M., Nabeya, N., Isshiki, G., et al. 1998. Extended HLA haplotypes in Japanese homozygous typing cells. Tissue Antigens 51: 305-308.

O'Shea, S.F., Chaure, P.T., Halsall, J.R., Olesnicky, N.S., Leibbrandt, A., Connerton, I.F., and Casselton, L.A. 1998. A large pheromone and receptor gene complex determines multiple B mating type specificities in Coprinus cinereus. Genetics 148: 1081-1090.

Penn, D. and Potts, W.K. 1998a. Untrained mice discriminate MHC-determined odors. Physiol. Behav. 64: 235-243.

— 1998b. How do major histocompatibility complex genes influence odor and mating preferences? Adv. Immunol. 69: $411-436$.

-1998c. MHC-disassortative mating preferences reversed by cross-fostering. Proc. R. Soc. Lond. B Biol. Sci. 265: 1299-1306.

Peters, H.C., Kammer, G., Volz, A., Kaupmann, K., Ziegler, A., Bettler, B., Epplen, J.T., Sander, T., and Riess, O. 1998. Mapping, genomic structure, and polymorphisms of the human GABABR1 receptor gene: Evaluation of its involvement in idiopathic generalized epilepsy. Neurogenetics 2: 47-54.

Pilpel, Y. and Lancet, D. 1999. The variable and conserved interfaces of modeled olfactory receptor proteins. Protein Sci. 8: 969-977.

Potts, W.K. and Wakeland, E.K. 1993. Evolution of MHC genetic diversity: A tale of incest, pestilence and sexual preference. Trends Genet. 9: 408-412.

Potts, W.K., Manning, C.J., and Wakeland, E.K. 1991. Mating patterns in seminatural populations of mice influenced by $\mathrm{MHC}$ genotype. Nature 352: 619-621.

Rouquier, S., Friedman, C., Delettre, C., van den Engh, G., Blancher, A., Crouau-Roy, B., Trask, B.J., and Giorgi, D. 1998a. A gene recently inactivated in human defines a new olfactory receptor family in mammals. Hum. Mol. Genet. 7: 1337-1345.

Rouquier, S., Taviaux, S., Trask, B.J., Brand-Arpon, V., van den Engh, G., Demaille, J., and Giorgi, D. 1998b. Distribution of olfactory receptor genes in the human genome. Nat. Genet. 18: 243-250.

Singh, P.B., Brown, R.E., and Roser, B. 1987. MHC antigens in urine as olfactory recognition cues. Nature 327: 161-164.

Tay, G.K., Cattley, S.K., Chorney, M.J., Hollingsworth, P.N., Roth, M.P., Dawkins, R.L., and Witt, C.S. 1997 Conservation of ancestral haplotypes telomeric of HLA-A. Eur. J. Immunogenet. 24: $275-285$.

Trask, B.J., Friedman, C., Martin-Gallardo, A., Rowen, L., Akinbami, C., Blankenship, J., Collins, C., Giorgi, D., Iadonato, S., Johnson, F., Kuo, W.L., et al. 1998. Members of the olfactory receptor gene 
family are contained in large blocks of DNA duplicated polymorphically near the ends of human chromosomes. Hum. Mol. Genet. 7: 13-26.

Tsuboi, A., Yoshihara, S.-I., Yamazaki, N., Kasai, H., Asai-Tsuboi, H., Komatsu, M., Serizawa, S., Ishii, T., Matsuda, Y., Nagawa, F. et al. 1999. Olfactory neurons expressing closely linked and homologous odorant receptor genes tend to project their axons to neighbouring glomeruli on the olfactory bulb. J. Neurosci. 19: $8409-8418$

Volz, A., Fonatsch, C., and Ziegler, A. 1992. Regional mapping of the gene for autosomal dominant spinocerebellar ataxia (SCA1) by localizing the closely linked D6S89 locus to 6p24.2-p23.05. Cytogenet. Cell Genet. 60: 37-39.

Wedekind, C. and Füri, S. 1997. Body odor preferences in men and women: Do they aim for specific MHC combinations or simply heterozygosity? Proc. R. Soc. Lond. B Biol. Sci. 264: 1471-1479.

Wedekind, C., Seebeck, T., Bettens, F., and Paepke, A.J. 1995. MHC-dependent mate preferences in humans. Proc. R. Soc. Lond. B Biol. Sci. 260: 245-249.

Wysocki, C.J. 1989. Vomeronasal chemorecognition: Its role in reproductive fitness and physiology. In Neural Control of Reproductive Function, pp. 545-566, Liss, New York.

Yamazaki, K., Boyse, E.A., Mike, V., Thaler, H.T., Mathieson, B.J., Abbott, J., Boyse, J., Zayas, Z.A., and Thomas, L. 1976. Control of mating preferences in mice by genes in the major histocompatibility complex. J. Exp. Med. 144: 1324-1335.

Yamazaki, K., Yamaguchi, M., Baranoski, L., Bard, J., Boyse, E.A., and Thomas, L. 1979. Recognition among mice: Evidence from the use of a Y-maze differentially scented by congenic mice of different major histocompatibility types. J. Exp. Med. 150: $755-760$.

Yamazaki, K., Beauchamp, G.K., Matsuzaki, O., Kupniewski, D., Bard, J., Thomas, L., and Boyse, E.A. 1986. Influence of a genetic difference confined to mutation of $\mathrm{H}-2 \mathrm{~K}$ on the incidence of pregnancy block in mice. Proc. Natl. Acad. Sci. 83: 740-741.

Yamazaki, K., Beauchamp, G.K., Singer, A., Bard, J., and Boyse, E.A. 1999. Odortypes: Their origin and composition. Proc. Natl. Acad. Sci. 96: $1522-1525$.

Zhao, H., L. Ivic, J.M. Otaki, M. Hashimoto, K. Mikoshiba, and S. Firestein. 1998. Functional expression of a mammalian odorant receptor. Science 279: 237-242.

Ziegler, A., Ehlers, A., Forbes, S., Trowsdale, J., Uchanska-Ziegler, B., Volz, A., Younger, R., and Beck, S. 2000a. Polymorphic olfactory receptor genes and HLA loci constitute extended haplotypes. In Major Histocompatibility Complex-evolution, Structure, and Function. (M. Kasahara, ed.) pp. 110-130. Springer Verlag Tokyo.

Ziegler, A., Ehlers, A., Forbes, S.A., Trowsdale, J., Volz, A., Younger, R., and Beck, S., 2000b. Polymorphism in olfactory receptor genes: A cautionary note. Hum. Immunol. (in press).

Ziegler, A., Müller, C., Heinig, J., Radka, S.F., Kömpf, J., and Fonatsch, C. 1985. Monosomy 6 in a human lymphoma line induced by selection with a monolonal antibody. Immunobiology 169: $455-460$.

Received August 4, 2000; accepted in revised form October 12, 2000. 